\section{Fatores protetores e de risco envolvidos na transmissão vertical do HIV-1}

\author{
Protective and risk factors related \\ to vertical transmission of the HIV-1
}

Rosângela P. Gianvecchio ${ }^{1}$

Tamara B. L. Goldberg ${ }^{2}$

\footnotetext{
1 Departamento de Pediatria, Universidade de Marília, Marília, Brasil. 2 Faculdade de Medicina de Botucatu, Universidade Estadual Paulista, Botucatu, Brasil.

Correspondência R. P. Gianvecchio Departamento de Pediatria Universidade de Marília. Rua Carlos Botelho 420, Marília, SP 17515-240, Brasil. rosangela@unimedmarilia. com.br
}

\begin{abstract}
This study aimed to evaluate maternal and fetal factors related to vertical transmission of HIV-1. Participants included 47 mother-child pairs. Behavioral, demographic, and obstetric data were obtained through interviews. Data related to delivery and newborns were collected from registries in the maternity hospitals. During the third trimester of pregnancy, CD4+ $T$ lymphocytes and maternal viral load were measured. Mean age of the mothers was 25 years and $23.4 \%$ of the pregnant women were primigravidae. The most prevalent behavioral factor was lack of condom use. 48.9\% of the women presented a CD4+ count greater than 500 cells/ $\mathrm{mm}^{3}$, and $93.6 \%$ belonged to clinical category $A$. 95.7\% of the women received zidovudine prophylaxis during pregnancy or childbirth, and the medication was also administered to all the neonates. $50.0 \%$ of patients were submitted to elective cesareans. Despite several risk and protective factors, none of the children was infected. Vertical transmission is an outcome of an imbalance among factors, with a predominance of risk over protective factors.
\end{abstract}

Acquired Immunodeficiency Syndrome; Risk Factors; HIV; Vertical Disease Transmission

\section{Introdução}

A transmissão do HIV-1 da mulher grávida para o seu concepto pode ocorrer em três momentos: intra-útero, intraparto e no pós-parto, neste caso por meio do aleitamento materno 1,2. Kuhn et al. 3, em um estudo sobre a transmissão da AIDS, com amostragem de 276 mulheres grávidas apresentando sorologia positiva para o HIV, determinaram o momento da transmissão vertical. A positividade do DNA HIV por técnica de PCR (Reação em Cadeia de Polimerase), nos primeiros três dias de vida, definiu a transmissão intrauterina, de forma que, ao nascimento, já foi possível detectar partículas virais. A negatividade do teste nos primeiros três dias com posterior positivação define a transmissão intraparto.

Os principais fatores envolvidos na transmissão vertical do HIV-1 são imunológicos, aleitamento materno, uso de anti-retroviral, comportamento e nutrição maternos, obstétricos, fetais, placentários e virológicos.

A doença materna avançada é fator de risco, pois taxas aumentadas de transmissão são encontradas entre mães com baixo CD4 ou com sintomas associados à AIDS 2. Em mulheres que transmitem infecção intra-útero é comum encontrar níveis baixos de anticorpos neutralizantes, quando comparados aos daquelas que transmitem intraparto ou das não-transmissoras. Assim, a transmissão pode ocorrer intraparto, a despeito da presença de anticorpos 4 . 
No caso do aleitamento materno, análises demonstram presença de vírus intra e extracelulares mediante microscopia eletrônica em amostras de leite humano e colostro ${ }^{5}$. Vírus livres de células podem penetrar na mucosa do trato gastrointestinal de recém-nascidos por meio de infecção de células com receptores CD4 ou por invasão direta na corrente sangüínea. Microtraumatismo das mucosas orofaríngeas ou gastrointestinais poderiam permitir que os retrovírus presentes no leite materno atingissem diretamente a circulação do lactente. O risco adicional de infecção pelo leite materno é de $7,0 \%$ a $22,0 \%$, dependendo do tempo de exposição, da infectividade do leite e da suscetibilidade individual da criança 4,6,7.

O protocolo 076, desenvolvido pelo AIDS Clinical Trials Group (ACTG 076), foi um estudo aleatório, abrangendo 477 gestantes e 421 crianças, o qual sugeriu administrar zidovudina (AZT) a um grupo de mulheres e placebo a outro, no período pré-parto, intraparto e pósparto. Os autores demonstraram uma redução significante no risco da transmissão perinatal do HIV-1 de $25,5 \%$ para $8,3 \%$, apresentando uma eficácia de $67,5 \% 8$.

Há associação entre o uso de drogas como cocaína, opiáceos, heroína, drogas injetáveis e a transmissão vertical do HIV-1. O uso de drogas é associado com dano placentário e disfunção metabólica. Quando há ruptura de membrana por tempo prolongado 9 , a taxa de transmissão é maior nas usuárias de drogas do que nas não-usuárias 10,11. Outro fator relacionado ao uso de drogas é não-aderir aos anti-retrovirais e não procurar o acompanhamento pré-natal. Em estudo que analisou as causas envolvidas no acompanhamento pré-natal de 4.755 pacientes, os autores verificaram que $20,0 \%$ das gestantes não realizaram seu pré-natal, sendo $17,0 \%$ usuárias de drogas e 3,0\% não-usuárias 12 .

Outro comportamento materno associado à transmissão perinatal é a relação sexual sem proteção e a relação sexual com múltiplos parceiros. A exposição materna a múltiplas cepas de HIV-1 de diferentes parceiros sexuais predispõe à aquisição de cepa viral mais prejudicial ao feto e as múltiplas exposições ao sêmen infectado poderiam levar a uma ativação imune e subseqüente aumento de replicação viral.

Também o tabagismo aumenta o risco de transmissão por alterações e mudanças morfológicas placentárias e complicações obstétricas, como amniorrexe prematura 13 .

Vários estudos avaliaram a contribuição de micronutrientes maternos e o risco de transmissão vertical do HIV-1. A hipovitaminose A aumenta o risco de transmissão 13,14 .
Em um estudo caso-controle, realizado entre 1990 e 1994, Thea et al. 15 estudaram 51 mães transmissoras e um grupo-controle de 54 mães não-transmissoras, encontrando associação da carga viral materna e a transmissão a seus filhos. Controlando-se a contagem de CD4, aumentava-se, aproximadamente em um terço, a probabilidade de transmissão perinatal para cada log adicional de carga viral. Essa associação era atenuada em mulheres com imunossupressão grave. Enquanto as defesas imunes da mulher não estiverem comprometidas, será necessária uma carga viral alta para haver a transmissão 10

A suscetibilidade das células fetais à infecção pelo HIV-1 varia com a idade gestacional, já que elas apresentam expressão do receptor CD4 de acordo com a época do desenvolvimento embrionário e com o tipo de tecido ou órgão. O timo imaturo, os macrófagos neonatais de sangue do cordão e células do sistema nervoso central são mais facilmente infectados 5 . Supõe-se que a infecção de células tímicas pelo HIV-1 leve precocemente a uma tolerância imunológica no feto.

De acordo com características genéticas, há uma maior ou menor predisposição à infecção. Por exemplo, é mais provável que gêmeos monozigóticos tenham sorologia HIV-1 concordante do que gêmeos dizigóticos. O antígeno HLA contribui para a expressão da doença, pois porção do envelope do HIV tem homologia com o complexo de histocompatibilidade maior de classe II. Conseqüentemente, indivíduos que têm alelos HLA que compartilhem determinantes com essas proteínas virais podem, teoricamente, ser mais susceptíveis à infecção 5,16.

O tipo de parto, o tempo de ruptura das membranas e a idade gestacional são os fatores obstétricos mais estudados. Nas crianças com infecção adquirida intraparto, existe associação positiva entre o tempo de ruptura de membranas e a transmissão do HIV-1 9 . Além disso, crianças nascidas pré-termo e pequenas para a idade gestacional têm maior risco de infecção intraparto ${ }^{3}$. No Brasil, recomenda-se a cesárea eletiva nas mulheres com carga viral acima de mil cópias 17 . Porém, a finalidade da terapia anti-retroviral para a gestante é justamente tornar a carga viral incapaz de ser detectada, pois quanto menor for esta, menor o risco de transmissão e, portanto, menor necessidade de realização de parto cesárea 18,19.

Newell 4 encontrou probabilidade aumentada de transmissão quando ocorreu trabalho de parto prolongado, ruptura das membranas por tempo prolongado, presença de sangue no líquido amniótico e sangramento pré e intra- 
parto, que, além de expor o feto ao sangue materno, estava associado à disruptura placentária.

Co-infecção materna com corioamnionite por sífilis perturba a integridade placentária, possibilitando a infiltração de células maternas infectadas pelo HIV-1 dentro do vilo 20,21. Não existe certeza de que o sinciciotrofoblasto expresse receptores CD4. Os linfócitos e as células de Hofbauer (macrófagos placentários) parecem ser as principais células que expressam antígenos virais em placentas infectadas.

Há evidências que sugerem que certos fenótipos e genótipos virais são mais facilmente transmissíveis. Os vírus isolados de mães nãotransmissoras tinham taxa de replicação lenta e títulos baixos quando cultivados em células mononucleares de sangue periférico, enquanto as cepas isoladas de mães transmissoras tinham crescimento rápido e títulos mais altos 2,5.

Pretende-se com este estudo, sob a ótica dos fatores protetores e de risco envolvidos na transmissão vertical do HIV-1, analisar a evolução do pré-natal, a situação clínica, a caracterização imunológica, os fatores obstétricos e o uso de zidovudina em um grupo de gestantes infectadas ou com doença de AIDS, além de conhecer a situação de seus recém-nascidos.

Finalmente tentar-se-á analisar o impacto da carga viral plasmática materna e de sua contagem de células CD4+ sobre o estado infeccioso de seus bebês, pela transmissão vertical do HIV-1.

\section{Métodos}

Foi realizado um estudo prospectivo entre julho de 1998 a julho de 2000, com inscrição de gestantes infectadas pelo HIV-1, em quatro centros de referência de DST/AIDS do Estado de São Paulo: o Núcleo de Gestão Assistencial (NGA), na cidade de Marília; Ambulatório de Moléstias Infecciosas de Tupã; Ambulatório de AIDS do NGA de Ourinhos e Ambulatório de Moléstias Infecciosas de Bauru.

Foram incluídas no estudo gestantes infectadas pelo HIV, sintomáticas ou não, encaminhadas pelas Unidades Básicas de Saúde (UBS) dos municípios aos centros de referências citados, além das mulheres que já faziam acompanhamento nesses locais e que engravidaram. As pacientes encaminhadas pelas UBS, onde iniciaram seu pré-natal e onde lhes foi oferecida testagem anti-HIV com os demais exames de rotina para gestantes, compareceram para continuar seu pré-natal nos centros de referência, trazendo em seus encaminhamentos os resultados dos exames realizados e a evolução do pré-natal até aquela data.
Nos centros de referência, quando elas se encontravam no terceiro trimestre de gestação, realizaram-se coletas de $5 \mathrm{ml}$ de sangue para medida da carga viral e $5 \mathrm{ml}$ para dosagem de linfócitos T CD4+ e CD8+. A coleta desses dois exames era realizada em dias diversos e agendada previamente, sendo a dosagem de CD4+e CD8+ realizada no Instituto Adolfo Lutz local e a determinação da carga viral plasmática, no Hemocentro da Faculdade de Medicina de Botucatu.

Todas as gestantes foram orientadas durante as consultas de pré-natal para o uso do AZT, assim que iniciaram seu acompanhamento ou a partir da 14a semana de gestação até o parto, numa dose diária de $600 \mathrm{mg}$, via oral. No momento do parto, iniciou-se, para os recém-nascidos, infusão de zidovudina, $2 \mathrm{mg} / \mathrm{kg}$ endovenoso na primeira hora, seguindo-se com infusão de $1 \mathrm{mg} / \mathrm{kg} /$ hora até o final do parto; num terceiro momento, ofereceu-se AZT para os recémnascidos por seis semanas, na dose de $2 \mathrm{mg} / \mathrm{kg}$ a cada seis horas.

Durante as visitas de pré-natal e por ocasião do acompanhamento dos recém-nascidos, foi aplicado um questionário fechado às pacientes para obtenção de dados sociais, demográficos, possíveis fatores de risco e de proteção para transmissão vertical do HIV, bem como história clínica da gestante. Os dados sobre o parto e condições do recém-nascido foram obtidos de informações relatadas pela mãe e do relatório de alta da maternidade. Para obtenção desses dados, as gestantes foram informadas do conteúdo da pesquisa, da necessidade da coleta de sangue do binômio mãe-filho, assinando um termo de consentimento livre e esclarecido.

Foram inscritas 64 gestantes e seus conceptos. Entretanto, a amostra final teve redução de 17 gestantes, já que 15 delas não realizaram carga viral na época preconizada pelo estudo, ou seja, no terceiro trimestre da gestação, pois houve dificuldade de comparecimento no dia exato determinado para a coleta; uma não compareceu aos retornos previamente agendados e uma das crianças foi a óbito, por causa diversa de AIDS.

As crianças foram consideradas não infectadas quando tinham anticorpos negativados até 18 meses de idade (Elisa, Western-blot e Imunofluorescência indireta) ou quando não se detectou vírus em pelo menos duas amostras de sangue, pelo mesmo método (NASBA Nucleic Acid Sequence Based Amplification ou PCR - reação em cadeia de polimerase qualitativo), sendo a última amostra obtida após o quarto mês de vida ${ }^{22}$. Nenhum recém-nascido rece- 
beu aleitamento materno de acordo com orientações do Programa Estadual de DST/AIDS de São Paulo (Secretaria do Estado da Saúde de São Paulo; 1999).

Esta pesquisa obedeceu às orientações e normas éticas da resolução 196/196, tendo sido aprovada pelo Comitê de Ética em Pesquisa da Faculdade de Medicina de Botucatu, Universidade Estadual Paulista.

\section{Resultados}

Foram incluídas no estudo 45 pacientes com idade compreendida entre 16 a 36 anos, com mediana de 25 anos, média de 25 anos e desvio padrão de 5,5 anos. Duas pacientes estiveram gestantes por duas vezes no período delimitado, portanto o estudo incluiu 47 pares mãe-filho.

Quanto à história obstétrica, 11 pacientes eram primigestas $(23,4 \%), 12$ eram gestantes do segundo filho $(25,5 \%) ; 10$, do terceiro $(21,2 \%)$; 4 , do quarto $(8,5 \%)$; 5 , do quinto filho $(10,7 \%)$, e 5 estavam grávidas pela sexta vez $(10,7 \%)$. No grupo das que esperavam o terceiro filho, 4 $(40,0 \%)$ tinham história de abortamento anterior, assim como $3(75,0 \%)$ das grávidas do quarto filho, $5(100,0 \%)$ das que esperavam o quinto e $80,0 \%$ das com 6 gestações (Tabela 1).

$\mathrm{O}$ quesito fatores comportamentais foi investigado entre o quinto e o nono mês gestacional, e houve uma variabilidade de 0 a 30 relações sexuais mensais (Tabela 2 ); $80,0 \%$ das pacientes tinham um parceiro sexual e 14,9\% (7) não tinham nenhum. Das mulheres que tinham parceiro sexual durante o período estudado, $31,9 \%$ referiram o uso de preservativo pelo companheiro, ao passo que $27,7 \%$ negavam; apenas $4,2 \%$ delas referiram o uso de drogas ilícitas.

Tabela 1

História obstétrica: número de gestações e de abortamentos das gestantes incluídas na amostra final.

\begin{tabular}{lccrr}
\hline \multirow{2}{*}{ Gestações } & \multicolumn{2}{c}{ Abortos anteriores } & \multicolumn{2}{c}{ Total } \\
& Não & Sim & $n$ & $\%$ \\
\hline G1 & 11 & - & 11 & 23,4 \\
G2 & 12 & - & 12 & 25,5 \\
G3 & 6 & 4 & 10 & 21,2 \\
G4 & 1 & 3 & 4 & 8,5 \\
G5 & - & 5 & 5 & 10,7 \\
G6 & 1 & 4 & 5 & 10,7 \\
Total & 31 & 16 & 47 & 100,0 \\
\hline
\end{tabular}

Tabela 2

Número de relações sexuais mensais.

\begin{tabular}{lrr}
\hline Relações sexuais & $\mathbf{n}$ & $\%$ \\
\hline Não respondeu & 12 & 25,5 \\
0 & 7 & 14,9 \\
$1-4$ & 13 & 27,7 \\
$5-10$ & 10 & 21,3 \\
$11-20$ & 4 & 8,5 \\
$>20$ & 1 & 2,1 \\
Total & 47 & 100,0 \\
\hline
\end{tabular}

Em relação à categoria da exposição materna, $85,1 \%$ foi sexual; $8,5 \%$, sexual e drogas; $6,4 \%$, transfusão de sangue. A classificação clínica imunológica foi realizada pelo critério Centers for Disease Control and Prevention 23, quando 23 pacientes $(48,9 \%)$ tinham contagem de células CD4+ maior que 500. Em 19 (40,5\%), essa contagem situava-se entre 200 e 500 células e, em 5 delas $(10,6 \%)$, obteve-se contagem menor do que 200 células CD4+/ $\mathrm{mm}^{3}$. Além disso, 44 gestantes se enquadravam na categoria $\mathrm{A}$, ou ausência de sintomas clínicos, muito embora 18 destas tivessem alteração imune moderada (A2) e 3 tivessem alteração imune grave (A3), quando avaliada pela contagem de célula CD4+ (Tabela 3).

Em 7 pacientes (15,0\%), não foi possível detectar a carga viral plasmática pela técnica NASBA. Nas demais, com carga viral detectável, a variabilidade foi de 300 a $380 \mathrm{mil}$ cópias $/ \mathrm{ml}$, com mediana de 6.400 cópias $/ \mathrm{ml}$, média de 36.866 cópias/ml e desvio-padrão de 69.501 cópias/ml.

A idade gestacional variou de 28 a 42 semanas, com mediana de 40 semanas, média de 39 e desvio-padrão de duas semanas. Realizou-se cesárea eletiva em $46,9 \%$, parto normal em $46,8 \%$ e cesárea de urgência em $6,3 \%$ (Tabela 4 ). O tempo de ruptura de membranas foi menor que quatro horas na grande maioria das gestantes $(95,7 \%)$.

Todas as pacientes incluídas neste estudo, em algum dos três momentos, fizeram profilaxia da transmissão vertical, sendo 37 pacientes $(78,7 \%)$ com AZT e 10 (21,3\%) com terapia dupla ou tripla, que incluía o AZT. Quanto ao momento de início da profilaxia, 43 pacientes $(91,5 \%)$ fizeram uso no período pré-parto, com início da terapia entre a 14a e a 36a semana de gestação, e também durante o trabalho de parto. A terapia foi oferecida aos recém-nascidos por seis semanas. Em um par $(2,1 \%)$ foi realizada 
profilaxia apenas para o recém-nascido, porque a mãe não aderiu ao tratamento durante a gestação, apesar de ter concordado na coleta dos exames; o nascimento ocorreu no domicílio. Outra paciente $(2,1 \%)$ referiu ser portadora do vírus no momento do parto e, por isso, só a partir daí, iniciou-se a profilaxia.

Todos os recém-nascidos tiveram critérios sorológicos ou virológicos para exclusão da infecção pelo HIV-1.

\section{Discussão}

A história obstétrica dessas pacientes revela grande vulnerabilidade no plano social/comportamental relacionada à AIDS, pois 29,9\% das mulheres estavam na quarta, quinta ou sexta gestação, e 34,0\% tinham antecedentes de pelo menos um abortamento.

Não usar preservativos coloca-se como fator comportamental materno de risco para transmissão perinatal 11,13. Quanto às mulheres que confirmaram ter atividade sexual, pouco mais da metade $(57,1 \%)$ solicitava o uso desse recurso profilático por parte do companheiro. Fato comprometedor é que as que tinham maior número de relações sexuais por mês estavam incluídas no grupo das que não usavam proteção.

AIDS materna por ocasião do parto e contagem de linfócitos CD4+ menor que 200 célu$\mathrm{las} / \mathrm{mm}^{3}$ têm sido associadas a um risco aumentado de transmissão vertical em vários estudos 3,10,15,24. Embora, em nosso estudo, uma grande variabilidade na carga viral das gestantes acompanhadas fosse observada, a maioria das pacientes se enquadrava na classificação clínica A, e a metade delas não tinha alteração imune importante, incluindo-se na categoria laboratorial de contagem de linfócitos CD4+ maior que 500 células/mm3.

Em um estudo realizado por Mofenson et al. 25, foram acompanhadas 480 gestantes em uso de anti-retroviral, todas com CD4+ menor que 500 células $/ \mathrm{mm}^{3}$. A taxa total de transmissão foi de 4,8\%. Os possíveis fatores de risco associados à transmissão perinatal do HIV foram analisados pelos autores. Somente CD4+ menor que 200 células $/ \mathrm{mm}^{3}$, níveis de HIV RNA acima do limiar de detecção (maior que 500 cópias $/ \mathrm{ml}$ ) no início do estudo e no parto, anticorpos HIV p24 na entrada e no parto diminuído e corioamnionite foram associados a um risco aumentado de transmissão. Assinale-se que a transmissão ocorreu em todos os níveis de HIV RNA detectável e não houve nenhum caso de transmissão nas mulheres com carga abaixo do limiar de detecção.
Tabela 3

Classificação da infecção nas pacientes pelo critério Centers for Disease Control and Prevention, 1992.

\begin{tabular}{lrrrrr}
\hline $\begin{array}{l}\text { Classificação } \\
\text { da infecção }\end{array}$ & A & B & C & \multicolumn{2}{c}{ Total } \\
\hline 1 & 23 & 0 & 0 & 23 & 48,9 \\
2 & 18 & 0 & 1 & 19 & 40,5 \\
3 & 3 & 2 & 0 & 5 & 10,6 \\
Total & $44(93,6)$ & $2(4,3)$ & $1(2,1)$ & 47 & 100,0 \\
\hline
\end{tabular}

Tabela 4

Tipo de parto e tempo de trabalho de parto.

\begin{tabular}{|c|c|c|c|c|c|c|}
\hline \multirow[t]{2}{*}{ Horas } & \multicolumn{2}{|c|}{ Normal } & \multicolumn{2}{|c|}{ Cesárea } & \multicolumn{2}{|c|}{ Total } \\
\hline & $\mathrm{n}$ & $\%$ & $\mathrm{n}$ & $\%$ & $\mathrm{n}$ & $\%$ \\
\hline 0 & - & 0,0 & 22 & 46,9 & 22 & 46,9 \\
\hline $1-9$ & 14 & 29,8 & 2 & 4,2 & 16 & 34,0 \\
\hline$>10$ & 8 & 17,0 & 1 & 2,1 & 9 & 19,1 \\
\hline Total & 22 & 46,8 & 25 & 53,2 & 47 & 100,0 \\
\hline
\end{tabular}

No presente trabalho, observa-se que $89,4 \%$ das pacientes tinham CD4+ superior a 200 células $/ \mathrm{mm}^{3}$ e $14,9 \%$ tinham carga viral impossível de se detectar; que $91,4 \%$ delas se submeteram à profilaxia com AZT na gestação e no parto, ministrando o medicamento a seus recémnascidos, e que a totalidade delas, em algum dos três momentos, realizou profilaxia, o que permite inferir que a taxa de transmissão seria com grande possibilidade inferior a $4,8 \%$.

Em virtude da pequena população de gestantes, não foi possível associar a contagem da carga viral plasmática materna à transmissão vertical, o que sugere a ampliação deste estudo. Vale ressaltar que, no The European Collaborative Study 24 , no subgrupo em que a carga viral média estava acima de 6.500 cópias $/ \mathrm{ml}$, empregando a técnica NASBA, o risco de transmissão vertical foi elevado, sendo de $17,5 \%$ para cargas de > 10 mil a 100 mil, e de $41,7 \%$ quando superiores a $100 \mathrm{mil}$ cópias/ml. Vinte gestantes acompanhadas por nós tinham carga viral superior a 6.500 cópias $/ \mathrm{ml}$.

O tempo da profilaxia com o AZT foi muito variável. Algumas gestantes já estavam em tratamento e, portanto, fizeram profilaxia desde o início da gravidez; para as demais, o início variou entre a 14a e a 36a semana. Frenkel et al. 26, 
em um estudo retrospectivo para analisar os componentes do ACTG 076, observaram que a taxa de transmissão era semelhante, independente de a mãe ter recebido ou não AZT endovenosa durante o parto, além da profilaxia durante a gestação. A duração do uso de zidovudina, no período gestacional, no grupo de gestantes estudado, foi variável e também não influenciou nas taxas de transmissão, as quais vêm decrescendo nos diversos centros, após a aplicação do protocolo ACTG 076. No entanto, apesar da oportunidade de implementar essa ação programática na redução da transmissão vertical, ainda há dificuldade no recrutamento das gestantes para os serviços de pré-natal e da testagem sorológica precoce 27 .

Vários estudos estão sendo conduzidos com a finalidade de avaliar outros esquemas profiláticos, associados ao AZT ou não, que possam reduzir a transmissão vertical, como a lamivudina (3TC) e a nevirapina, em conjunto ou não com a imunização passiva com imunoglobulina hiperimune anti-HIV, testando os momentos pré-parto, parto ou pós-parto ou combinação deles, em gestantes infectadas pelo HIV $6,13,28,29$.

Procedimentos obstétricos invasivos, como amnioscopia e amniocentese, ruptura prolongada das membranas, hemorragia durante o parto e parto prolongado, são alguns dos principais fatores de risco obstétricos documentados na transmissão perinatal do HIV-1 13,25,30. Como a grande maioria das pacientes neste estudo contou com fatores obstétricos protetores, no sentido de diminuir a exposição do feto às secreções e ao sangue materno, provavelmente houve redução de vulnerabilidade à infecção. À exceção de uma paciente, que foi submetida a uma amniocentese, e de outra, que teve hemorragia durante o trabalho de parto, o pré-natal e as condições de parto foram adequadas, o que se confirma pela avaliação das condições de nascimento dos recém-nascidos, com peso, comprimento e condições de vitalidade satisfatórios.

Kind et al. 31 avaliaram o impacto que o parto cirúrgico teria sobre a transmissão vertical e observaram que a taxa de transmissão, entre as gestantes que se submeteram a essa interven- ção, foi de $6,0 \%$, ao passo que entre aquelas que se submeteram a outro tipo de parto foi de $20,0 \%$. Entre todas as gestantes que foram submetidas a parto cirúrgico associado à profilaxia com AZT, a taxa de transmissão foi nula. Em outro estudo divulgado mais recentemente, a taxa de transmissão entre as mulheres submetidas ao parto cesáreo associado ao uso do AZT foi de $2,0 \% 32$.

Quase a metade das gestantes acompanhadas neste estudo foi submetida a parto por cesárea eletiva e não se constatou qualquer caso com complicação obstétrica. O tempo de ruptura das membranas foi menor do que quatro horas em 95,0\% das mulheres e a duração do trabalho de parto foi inferior a dez horas em $80,0 \%$ das pacientes.

O diagnóstico da condição de infecção no recém-nascido, quando possível, foi feito por testes virológicos que fornecem resultados de infecção em idade mais precoce, com alta sensibilidade e especificidade. Quando não foi possível a obtenção desses testes, o diagnóstico foi baseado na negativação dos testes sorológicos.

Com base nos dados obtidos e apresentados, ressalta-se a importância de uma melhor cobertura dos serviços pré-natais e da assistência ao parto, bem como da divulgação dos mecanismos envolvidos na transmissão perinatal. Pode-se concluir que houve, na população estudada, pacientes submetidas a alguns fatores de risco e a alguns fatores protetores. Em resumo, as principais medidas de prevenção de responsabilidade dos serviços de saúde são: aconselhamento e testagem sorológica em mulheres grávidas o mais precoce possível, a possibilidade de orientar quanto ao planejamento familiar, cuidados obstétricos, uso de anti-retrovirais, disponibilidade de alternativa para o aleitamento materno 33,34. Não há um fator de risco ou protetor que, isoladamente, determine a transmissão ou possa preveni-la. Por outro lado, as estratégias atualmente disponíveis, quando aplicadas precocemente, quase interrompem a cadeia de transmissão perinatal do HIV1, e, provavelmente, essa população submetida a uma multiplicidade de fatores teve seus conceptos inteiramente protegidos do dano. 


\section{Resumo}

Este estudo avalia os fatores maternos e fetais envolvidos na transmissão vertical do HIV-1 em 47 pares de mãe e filho. As variáveis comportamentais, demográficas e obstétricas foram obtidas mediante entrevista; os dados referentes ao parto e ao recém-nascido, dos prontuários das maternidades. Durante o terceiro trimestre de gestação foi realizada a contagem da carga viral materna e dos linfócitos T CD4+. A média de idade foi de 25 anos e $23,4 \%$ das gestantes eram primigestas, e o fator comportamental mais prevalente foi não usar preservativos. Dentre as gestantes, $48,9 \%$ tinham células CD4+ superior a 500 células $/ \mathrm{mm}^{3}$ e 93,6\% se enquadravam na categoria clínica A; 95,7\% submeteram-se à profilaxia com zidovudina durante a gestação ou no parto, a qual foi ministrada a todos os recém-nascidos; $50,0 \%$ delas foram submetidas à cesárea eletiva. Apesar de expostas a vários fatores de risco e protetores, nenhuma criança tornou-se infectada. A transmissão vertical resulta de um desequilíbrio entre os fatores, com predomínio dos de risco sobre os protetores.

Síndrome de Imunodeficiência Adquirida; Fatores de Risco; HIV; Transmissão Vertical de Doença

\section{Colaboradores}

R. P. Gianvecchio e T. B. L. Goldberg contribuíram substancialmente para a concepção, planejamento, análise, interpretação dos dados, redação e revisão do manuscrito, bem como de sua versão final.

\section{Referências}

1. Bryson YJ. Perinatal HIV-1 transmission: recents advances and therapeutic interventions. AIDS 1996; 10 Suppl 3:S33-42.

2. Orloff SL, Simonds RJ, Steketee RW, Louis ME. Determinants of perinatal HIV-1 transmission. Clin Obstet Gynecol 1996; 39:386-95.

3. Kuhn L, Abrams EJ, Matheson PB, Thomas PA, Lambert G, Bamji M, et al. Timing of maternal infant HIV transmission: association between intrapartum factors and early polymerase chain reaction results. AIDS 1997; 11:429-35.

4. Newell ML. Mechanism and timing of mother to child transmission of HIV-1. AIDS 1998; 12:831-7.

5. Mofenson L, Wolinsky SM. Current Insights Regarding Vertical transmission. In: Pizzo PA, Wilfert CM, editors. Pediatric Aids. 2nd Ed. Baltimore: Williams \& Wilkins; 1994. p. 179-303.

6. Bhana N, Ormrod O, Perry CM, Figgitt DP. Zidovudine: a review of its use in the management of vertically-acquired pediatric HIV infection. Paediatr Drugs 2002; 4:515-53.

7. Read JS. Human milk, breastfeeding, and transmission of human immunodeficiency virus type 1 in the United States. American Academy of Pediatrics Committee on Pediatric AIDS. Pediatrics 2003; 112:1196-205.

8. Connor EM, Sperling RS, Gelber R, Kiselev P, Scott G, Sullivan MJ, et al. Reduction of maternal-infant transmission of human immunodeficiency virus type 1 with zidovudine treatment. $\mathrm{N}$ Engl J Med 1994; 331:1173-80.

9. Mussi-Pinhata MM, Kato CM, Duarte G, Paschoini MC, Bettiol H, Quintana SM. Factors associated with vertical HIV transmission during two different time periods: the impact of zidovudine use on clinical practice at a Brazilian reference centre. Int J STD AIDS 2003; 14:818-5.

10. Burns DN, Landesman S, Wright DJ, Waters D, Mitchell RM, Rubinstein A, et al. Influence of other maternal variables on the relationship between maternal virus load and mother-to-infant transmission of human immunodeficiency virus type 1. J Infect Dis 1997; 175:1206-10.

11. Matheson PB, Shoenbaum E, Greenberg B, Pliner V, The New York City Perinatal HIV Transmission Collaborative Study Group. Association of maternal drug use during pregnancy with mother to child HIV transmission. AIDS 1997; 11:941-3.

12. Peters V, Liu KL, Dominguez K, Frederick T, Melville S, Hsu HW, et al. Missed opportunities for perinatal HIV prevention among HIV-exposed infants born 1996-2000, pediatric spectrum of HIV disease cohort. Pediatrics 2003; 111:1186-91.

13. Mofenson L, Wilfert C. Pathogenesis and interruption of vertical transmission. In: Pizzo PA, Wilfert CM, editors. Pediatric Aids. 3rd Ed. Baltimore: Williams \& Wilkins; 1998. p. 487-513.

14. Greenberg BL, Semba RD, Vink PE, Farley JJ, Sivapalasingam M, Steketee RW, et al. Vitamin A deficiency and maternal infant transmission of HIV in two metropolitan areas in the United States. AIDS 1997; 11:325-32.

15. Thea DM, Steketee RW, Pliner V, Bornschlegel K, Brown T, Orloff S, et al. The effect of maternal vi- 
ral load on the risk of perinatal transmission of HIV-1. AIDS 1997; 11:437-44.

16. Matt C, Roger M. Genetic determinants of pediatric HIV-1 infection: vertical transmission and disease progression among children. Mol Med 2001; 7:583-9.

17. Ministério da Saúde. Recomendações para profilaxia da transmissão do HIV e terapia anti-retroviral em gestantes. Brasília: Ministério da Saúde; 2004.

18. Dominguez KL, Lindegren ML, D’Almada PJ, Peters VB, Frederick T, Rakusan TA, et al. Increasing trend of cesarean deliveries in HIV-infected women in the United States from 1994 to 2000. J Acquir Immune Defic Syndr 2003; 33:232-8.

19. Minkoff H. Human immunodeficiency virus infection in pregnancy. Obstet Gynecol 2003; 101: 797-810.

20. Anderson CL, Sedmak DD, Lairmore MD. Vertical transmission of HIV. In: Pizzo PA, Wilfert CM, editors. Pediatric Aids. 2nd Ed. Baltimore: Williams \& Wilkins; 1994. p. 159-69.

21. De-Andreis C, Simoni G, Rossella F, Castagna C, Pesenti E, Porta G, et al. HIV-1 proviral DNA polymerase chain reaction detection in chorionic villi after exclusion of maternal contamination by variable number of tandem repeats analysis. AIDS 1996; 10:711-5.

22. Centers for Disease Control and Prevention. Revised classification system for human immunodeficiency virus infection in children less than 13 years of age. MMWR Recomm Rep 1994; 43(RR3):1-21.

23. Centers for Disease Control and Prevention. 1993 Revised Classification System for HIV infection and expanded surveillance case definition for AIDS among adolescents and adults. MMWR Recomm Rep 1992; 41(RR-17):1-19.

24. The European Collaborative Study. Maternal viral load and vertical transmission of HIV-1: an important factor but not the only one. AIDS 1999; 13:1377-85.

25. Mofenson L, Lambert JS, Stiehm ER, Bethel J, Meyer WA, Whitehouse J, et al. Risk factors for perinatal transmission of human immunodeficiency virus type I in women treated with zidovudine. N Engl J Med 1999; 431:385-93.
26. Frenkel LM, Cowles MK, Shapiro DE, Melvis L, Watts DH, McLellan C, et al. Analysis of the maternal components of the AIDS clinical group 076 zidovudine regimen in prevention of mother to infant trnsmission of human immunodeficiency virus type 1. J Infect Dis 1997; 175:971-4.

27. Arbona SI, Melville SK, Hanson IC, Squires JE, Doyle M, Doran TI, et al. Mother-to-child transmission of the human immunodeficiency virus in Texas. Pediatr Infect Dis J 2001; 20:602-6.

28. Watts DH. Drug therapy: management of human immunodeficiency virus infection in pregnancy. N Engl J Med 2002; 346:1879-91.

29. Moodley D, Moodley J, Coovadia H, Gray G, Mclntyre J, Hofmyer J, et al. A multicenter randomized controlled trial of nevirapine versus a combination of zidovudine and lamivudine to reduce intrapartum and early postpartum motherto-child transmission of human immunodeficiency virus type 1. J Infect Dis 2003; 187:721-4.

30. Mofenson LM, Korelitz J, Meyer WA, Bethel J, Rich $\mathrm{K}$, Pahwa S, et al. The relationship between serum human immunodeficiency virus type 1, RNA level, CD4 lymphocyte percent and long term mortality risk in HIV-1 infected children. J Infect Dis 1997; 175:1029-38.

31. Kind C, Rudin C, Siegrist CA, Wyler CA, Biedermann K, Lauper U, et al. Prevention of vertical HIV transmission: additive protective effect of elective cesarean section and zidovudine prophylaxis. AIDS 1998; 12:205-10.

32. Magnani G, Degli-Antoni AM, Cocca G, Zoncada A, Cavatorta E, Grignaffini A, et al. Rischio di trasmissioni materno-fetale dell'infezione da HIV mediante terapia anti-retrovirale e taglio cesareo: esperienza del gruppo di Parma. Acta Biomed Ateneo Parmense 2000; 71:563-6.

33. Mofenson L. U.S. Public Health Service Task Force recommendations for use of anti-retroviral drugs in pregnant HIV-1-infected women for maternal health and interventions to reduce perinatal HIV-1 transmission in the United States. MMWR Recomm Rep 2002; 51 (RR-18):1-38.

34. Pancharoen C, Thisyakorn U. Pediatric acquired immunodeficiency syndrome in Asia: mother-tochild transmission. Clin Infect Dis 2002; 34 Suppl 2:S65-9.

Recebido em 29/Jul/2002

Versão reapresentada em 30/Ago/2004

Aprovado em 08/Dez/2004 